\title{
Decision-Making About Reproductive Choices Among Individuals At-Risk for Huntington's Disease
}

\author{
Robert Klitzman, ${ }^{1,5}$ Deborah Thorne, ${ }^{2}$ Jennifer Williamson, ${ }^{3}$ \\ Wendy Chung, ${ }^{4}$ and Karen Marder ${ }^{4}$
}

\begin{abstract}
Published Online: 1 May 2007
We explored how individuals at-risk for HD who have or have not been tested make reproductive decisions and what factors are involved. We interviewed 21 individuals ( 8 with and 4 without the mutation, and 9 un-tested) in-depth for 2 hours each. At-risk individuals faced a difficult series of dilemmas of whether to: get pregnant and deliver, have fetal testing, have pre-implantation genetic diagnosis, adopt, or have no children. These individuals weighed competing desires and concerns: their own desires vs. those of spouses vs. broader moral concerns (e.g., to end the disease; and/or follow dictates against abortion) vs. perceptions of the interests of current or future offspring. Quandaries arose of how much and to whom to feel responsible. Some changed their perspectives over time (e.g., first "gambling," then being more cautious). These data have critical implications for genetic counselors and other health care workers and future research, particularly as more genetic tests become available.
\end{abstract}

KEY WORDS: reproductive choices; genetics; pre-implantation genetic diagnosis; ethics; decisionmaking; risk assessments; qualitative research.

\section{INTRODUCTION}

After the location of the Huntington's Disease (HD) gene was identified, many at-risk individuals suggested that they would utilize prenatal testing (Craufurd et al., 1989; Kessler et al., 1987; Markel et al., 1987; Mastromauro et al., 1987; Meissen and

\footnotetext{
${ }^{1}$ Associate Professor of Clinical Psychiatry, College of Physicians and Surgeons and Mailman School of Public Health, Columbia University, New York, NY, USA.

${ }^{2}$ Department of Neurology, Psychiatry, College of Physicians and Surgeons, Columbia University, New York, NY, USA.

${ }^{3}$ Department of Neurology, Psychiatry, College of Physicians and Surgeons, Gertrude H. Sergievsky Center, Columbia University, New York, NY, USA.

${ }^{4}$ Department of Neurology, Psychiatry, College of Physicians and Surgeons, Gertrude H. Sergievsky Center, Taub Institute for Alzheimer's Disease and the Aging Brain, Columbia University, New York, NY, USA.

${ }^{5}$ Correspondence should be directed to Robert Klitzman, M.D., HIV Center, Unit 151051 Riverside Drive, New York, NY 10032, USA; e-mail: rlk2@columbia.edu.
}

Berchek, 1987; Tyler et al., 1990), yet fewer have done so (Evers-Kierbooms et al., 2002). Prenatal testing for $\mathrm{HD}$, using amniocentesis or chorionic villus sampling (CVS) of a fetus has been possible, followed by a choice of whether to continue or terminate the pregnancy. More recently, disclosing and non-disclosing preimplantation genetic diagnosis for HD have also been developed (Sermon et al., 2002; Simpson and Harper, 2001), in which mutation negative embryos are implanted in the uterus, either with or without patients' knowledge of their own HD genetic status. Patients who do not wish to know their own gene status are thus able to assure that any viable pregnancy is mutation negative (Stern et al., 2002), while not learning their own gene status. Yet patients have found the treatment cycle of preimplantation genetic diagnosis to be stressful (Lavery et al., 2002).

Studies have suggested that individuals not at risk for HD have thought that at-risk individuals should prevent transmitting HD to offspring. For 
example, of Swiss law and medical students, 94\% support the systematic proposal of prenatal testing for at-risk pregnant individuals (Elger and Harding, 2003). Of Mexican neurologists, psychiatrists, and psychologists, $38 \%$ thought that mutation positive individuals should not have offspring (Alonso Vilatela et al., 1999), though this study did not consider pre-implantation genetic diagnosis. A study in 3 European countries found that most geneticists, obstetricians, lay individuals, and pregnant women would undergo an abortion of a fetus with the HD mutation (Drake et al., 1996)

However, in the past decade, rates of prenatal testing among at-risk populations have also been found to be relatively low $-5-25 \%$ in the United Kingdom (Hayden, 2000) and Australia (Richards and Rea, 2005), and approximately $18 \%$ in Canada (Creighton et al., 2003). In a French study of couples pregnant at the time of presymptomatic testing, $73 \%$ opted to continue the pregnancy, and only $9 \%$ opted for prenatal testing (Lesca et al., 2002). Women more than men have been found to undergo predictive testing for themselves and to request prenatal testing (Creighton et al., 2003; Richards and Rea, 2005).

Many individuals at risk for HD have decided to have children, though they may carry the mutation. In the Netherlands, e.g., $19 \%$ of at-risk individuals have had genetic testing done and $44 \%$ of these already had children (Maat-Kievit et al., 1999). Compared to HD non-carriers, HD carriers may have approximately equal or fewer numbers of subsequent pregnancies (Taylor and Myers, 1997; Goizet et al., 2002). In Europe, Evers-Kiebooms et al. (2002), e.g., found that $14 \%$ of HD carriers vs. $28 \%$ of noncarriers had later pregnancies. Among carriers, prenatal diagnosis did not occur in one-third of pregnancies. Among those who were motivated by "family planning" to get predictive testing, 39\% of carriers vs. $69 \%$ of non-carriers had subsequent pregnancies (Evers-Kiebooms et al., 2002). Thus, test results may predict pregnancy decisions, although differences may arise between countries.

Possible reasons reported for low uptake of prenatal testing include: objections to abortion, hope that a cure will be found, psychological defense mechanisms, and desires to seek first predictive testing for the parent (Adam et al., 1993; Richards and Rea, 2005). Of note, these Australian and Canadian reports did not mention cost as a potential barrier. Ethical questions exist as to what traits should be screened for using pre-implantation genetic diagnosis or other prenatal procedures, to avoid "unacceptable consumerism" (Henn, 2000). Controversy exists about embryo selection based on sex or inheritable deafness (Robertson, 2003). Non-disclosure pre-implantation genetic diagnosis presents certain ethical challenges, given that egg extraction is not entirely benign, and a large team of health care workers is involved in pre-implantation genetic diagnosis, challenging the maintenance of confidentiality. Due to these potential problems, at least one HD clinic at one time did not offer non-disclosure preimplantation genetic diagnosis (Braude et al., 1998). Yet, how at-risk individuals actually view these issues has not been examined.

Downing (2005) emphasizes the importance of responsibility toward others as a factor in reproductive decision-making about HD. But other concerns may arise as well. Indeed, Downing's data involved testing through linkage analyses that necessitate families acting together to arrange for prenatal testing (Downing, 2005). However, technology now has advanced to allow direct testing for the mutation. Moreover, Downing presents 3 cases, but additional scenarios and conflicts may arise among other individuals.

A Health Belief Model has been described, suggesting that individuals' health behavior is shaped by their perceived susceptibility, disease severity, and costs and benefits of the behavior (Rosenstock et al., 1988). Such a model has not been explored with regard to HD reproductive decisions, but may offer insights. With regard to decisions about genetic testing for HD, Stages of Change models have also been suggested: e.g., that individuals enter a precontemplative phase (Houlihan, 1999; Taylor, 2005). With regard to HD reproductive decisions, individuals may indeed undergo a process, including precontemplation stages as well. Yet what exactly occurs during these stages remains unclear. Stages of change models as a whole have been criticized, since individuals may occupy several such stages simultaneously (Littell and Girvin, 2002), yet the possible applicability of such a theoretical model may be worth exploring with regard to HD reproductive decision-making. Individuals may face conflicts and have to balance desires to appear and act altruistically and responsibly toward others vs. wishes to follow their own needs.

In general (i.e., without regard to any particular disorders), genetic counseling has been found to affect $43.5 \%$ of clients' decisions about reproductive options (Wertz and Sorenson, 1986). But in these decisions, influence by others (e.g., spouses and other 
health care workers) has been under-examined. Indeed, family members often feel stress when an individual is diagnosed with HD (Sobel and Cowan, 2000). In general, couples often disagree on reasons for genetic counseling, both before and afterwards (Sorenson and Wertz, 1986), and genetic testing can have complex effects on a relationship (Richards, 2004). Relationship factors have been found to affect abortion decisions (Sihvro et al., 2003)—e.g., 12\% of women become pregnant because of pressures or threats from a man (Kero et al., 2001), and men often have ambivalent feelings about a spouse terminating a pregnancy (Kero et al., 1999).

Being at risk for HD in itself can cause considerable psychological distress, especially in the short-term, though not the long-term (Meiser and Dunn, 2000; Broadstock et al., 2000; Tibben et al., 1993; Robins-Wahlin et al., 2000). Hence, reproductive decision-making may be affected by such psychological responses. In general, individuals also tend to be risk averse (Kahneman and Tversky, 1974; Tversky and Kahneman, 1981), and either seek or avoid information about a medical condition (Case et al., 2005). Yet, with regard to reproductive decision-making about HD, the potential applicability of these issues, and whether individuals have to balance these issues, and if so, how have they been under-explored.

Several critical questions thus remain: In making reproductive decisions (i.e., concerning childbirth, prenatal diagnosis, abortion, and pre-implantation genetic diagnosis) do at-risk individuals who either have or have not had testing in fact balance responsibility toward others against other factors and concerns, and if so, what other factors are involved, and how? As a degenerative, autosomal dominant disorder with late onset and without effective treatment, HD no doubt differs from other genetic disorders, but can provide critical insights into issues that arise. The present study provides an opportunity to examine views on decision-making regarding reproductive issues concerning such a disorder. From a theoretical standpoint, too, Geertz has advocated studying aspects of individuals' lives and social situations not by imposing theoretical structures, but by trying to understand the individuals' own experiences, drawing on their own words and perspectives to obtain a "thick description" (Geertz, 1973). We have used qualitative methods to explore views and approaches towards other difficult issues, e.g., concerning reproductive and other ethical dilemmas regarding HIV (Klitzman, 1997; Klitzman and Bayer, 2003)

\section{METHODS}

\section{Sample}

Based on initial interviews, we chose to include 3 groups of interviewees: those who had tested and found they had the mutation and did not have the mutation, and those who had not tested. We chose this sampling strategy since these three categories shaped HD risk (i.e., by showing that the mutation was present, absent, or unknown), and, based on prior research, seemed to be important in affecting how individuals viewed and approached their HD risk. Thus, we anticipated that this sampling strategy would provide us some variation in range of participants and responses. As summarized in Table I, we thus interviewed in the end a total of 21 individuals8 mutation positive for HD, 4 mutation negative, and 9 not tested-for 2 hours each. Of the 9 women and 12 men interviewed, 1 had less than a high school education, 3 had a high school education, 2 had attended some college, 8 had completed 4 years of undergraduate studies, and 7 had completed at least some graduate work. Ten were working professionals, 5 were blue-collar workers, 5 were unemployed, and 1 was a student. Eleven were married, and 9 had children.

Participants were recruited from an HD clinic that has a predictive testing program. Individuals with a clinical diagnosis and at-risk individuals were approached by clinical staff at the HD Center regarding potential participation in the study. Attempts were made to ask all people who underwent presymptomatic testing, or who were at risk, and their $1^{\text {st }}$ degree relatives if they would participate.

\section{Measures}

To understand most fully the range of factors that may be involved, we used qualitative methods. With each participant, the PI of this project conducted a confidential 2-hour in-depth semi-structured interview concerning experiences of being at risk for HD and undergoing the process of testing, and/or learning one's genetic status. Relevant sections of the interview guide are attached (see Appendix A), through which we sought to obtain detailed descriptions of the above issues (Geertz, 1973).

In our methods, we have adapted elements from Grounded Theory (Strauss and Corbin, 1990). Our approach was thus informed by techniques of 


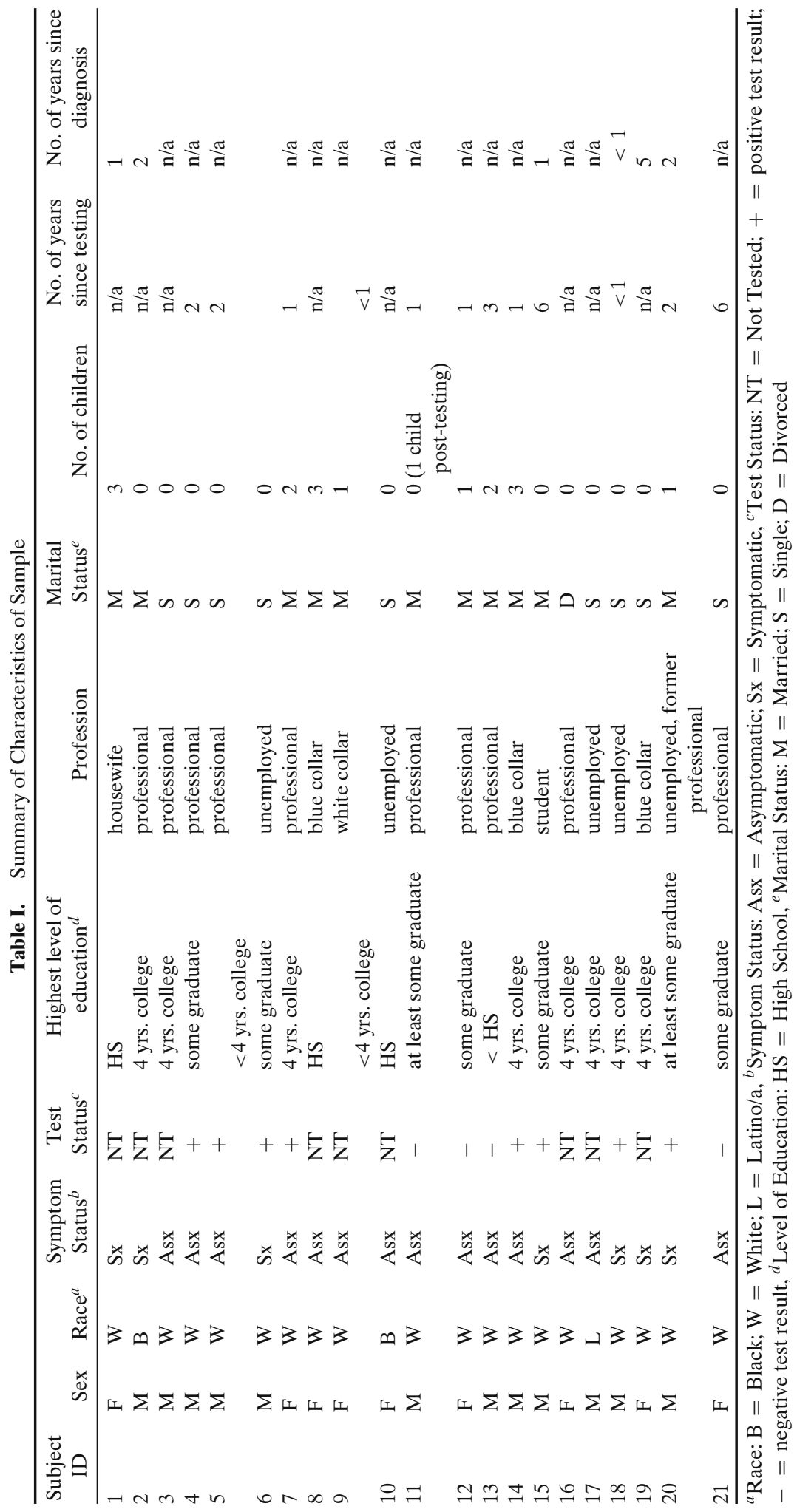


"constant comparison" in which data from different contexts are compared for similarities and differences, to see if they suggest hypotheses. This technique of "constant comparison" generates new analytic categories and questions, and checks them for reasonableness. During the ongoing process of in-depth interviewing, the researchers constantly considered how participants resembled or differed from each other, and the social, cultural and medical contexts and factors that contributed to differentiation. Grounded theory also involves both deductive and inductive thinking, building inductively from the data to an understanding of themes and patterns within the data, and deductively, drawing on frameworks from prior research and theories. In conducting thematic content-analyses, we also triangulated methods, referring to the published literature, described above.

We drafted the questionnaire, drawing on prior research we conducted, published literature, and discussions with clinic staff and others. We then piloted it, analyzing the results of the interviews, and revising the interview guide further as we proceeded. Transcriptions and initial analyses of interviews occurred during the period in which the interviews were being conducted, enhancing validity, and these analyses helped shape subsequent interviews. Interviews were conducted at participants' offices or homes or in the PI's office-whichever was more convenient for participants. The Columbia University Department of Psychiatry Institutional Review Board approved the study, and all participants gave informed consent.

\section{Analytic Approach}

Interviews were conducted until major and minor themes became clear. Once the full set of interviews were completed, subsequent analyses were conducted. Analyses were conducted in two phases, primarily by the PI together with a research assistant (RA) who had social science training. At several points during the coding process, we also received input from an additional, senior expert in qualitative research.

In phase I, the PI and the RA independently examined a subset of interviews to assess factors that shaped participants' experiences, identifying categories of recurrent themes and issues that were subsequently given codes. The coders assessed similarities and differences between participants, examining categories that emerged, ranges of variation within categories, and variables that may be involved. The coders developed a coding manual and examined areas of disagreement until reaching consensus between them. New themes that did not fit into the original coding framework were discussed, and modifications were made in the manual when deemed appropriate. In phase 2 of the analysis, we refined and merged subdivided thematic categories into secondary or sub-codes, when suggested by associations, or overlap in the data. Codes and sub-codes were then used in analysis of all of the interviews. To ensure coding reliability, 2 coders analyzed all interviews. We examined areas of disagreement until consensus was reached through discussion. Major codes included, for example, discussions of desires to have children, pre-implantation genetic diagnosis, abortion, or adoption. Within these core codes (e.g., wanting children, considering abortion), we then explored dimensions involved (e.g., reasons for and against, and external factors involved). Sub-codes (or sub-themes) included, for example specific attitudes for or against: having children, pre-implantation genetic diagnosis, abortion, or adoption.

\section{RESULTS}

Individuals at risk for HD wrestled with reproductive issues, which often proved more difficult than those concerning genetic privacy and other areas. As shown on Table II and described more fully below, individuals struggled with a series of questions concerning reproductive options-whether to have children or not, become pregnant, and undergo testing, pre-implantation genetic diagnosis or abortion, and how to make such decisions. While not an explicit decision-tree per se, this implicit pattern of choices nonetheless emerged, with individuals confronting multiple decision-points, affected by a range of personal and social considerations. Fig. 1 presents a model illustrating how patterns of tensions or agreements could exist concerning these issues among different sets of factors-individual desires vs. perceived responsibilities toward spouse, family of origin, current offspring, future offspring, and/or broader society. 
Table II. Themes Regarding Reproductive Decision-Making Among Individuals At-risk of Huntington's Disease

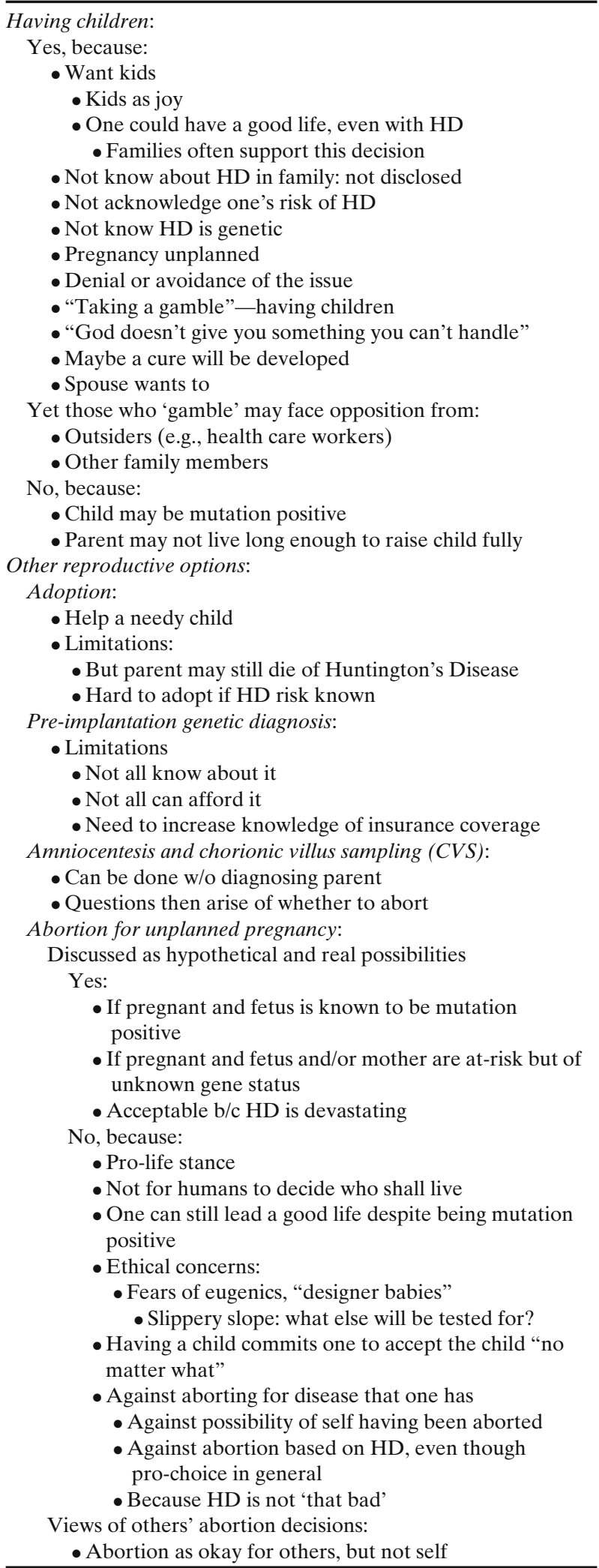

Continued. Themes regarding reproductive decision-making among individuals at-risk of Huntington's Disease

- Not passing judgment on others who do so

- Individual rights

- 'Its up to the individual' - even if one wouldn't undergo abortion oneself, based on HD

Other implications

- As a result of these concerns about reproduction, some do not even marry

Guilt and blame:

- Some parents feel guilty about having children born who are at risk

- Some individuals are concerned they would feel guilty

- Even if guilt is 'illogical'

- Guilt can be overwhelming

- Some parents are blamed

- Future blame feared if prenatal testing and

pre-implantation genetic diagnosis become more common

- Others feel there is no reason for guilt

\section{Reproductive Choices}

\section{Having Children}

On the one hand, notions of responsibility toward others led many at-risk individuals to oppose giving birth to children without preventing the possibility of the child having the mutation. They felt that they could and should help stop the continued spread of HD. Moreover, the parent may become sick, and not live long to be able to help offspring fully develop. At times, these concerns about dying and being unable to raise the child as long as possible outweighed fears about transmitting the gene.

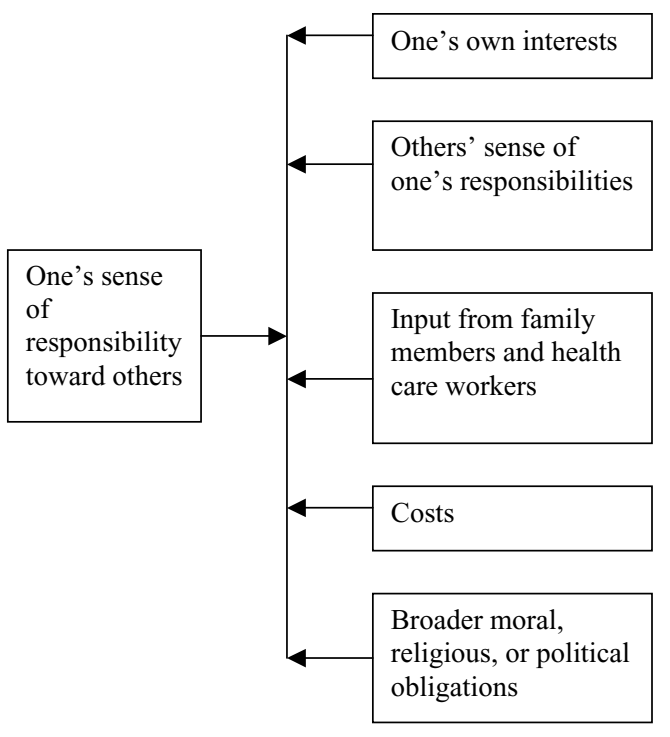

Fig. 1. Factors weighed in reproductive decisions. 
My biggest fear then was not, 'What if I pass this gene to my child,' but 'What if I get sick before he's old enough to take care of himself?'... [8:F/Asx/NT]

Yet others at risk for HD wanted to have children, and/or proceeded to do so, offering several reasons, e.g., their own desires for children, or lack of knowledge about HD. At times, children were born at risk for HD because disclosure to the parents by the children's grandparents had not taken placei.e., family members with knowledge of HD had not disclosed the HD risk to others in the family. For example,

\section{It was only three or four years ago that my mother first mentioned it to my brother and I. My brother already had a son. [19:F/Sx/NT]}

Individuals may know of HD in the family, but not that it posed a risk to their children. One woman said she did not know she was at risk of acquiring her grandfather's illness.

I've never thought not to have kids...I never thought in terms of the disease being hereditary and my children having the disease. [16:F/Asx/NT]

Decisions to have children may also be disconnected from concerns about HD. Individuals reflected on past as well as future decisions to have children. Some had children after being aware that HD was a risk, but before fully thinking through and acknowledging it. Denial may play a role here, in part because of desires to avoid wrestling with the potential burden of the disease to oneself or others. One woman said about her brother,

\section{He didn't know it was genetic. I don't know how he didn't know. How wouldn't you know it's genetic? He says, "If I had known that, I wouldn't have had any kids." [9:F/Asx/NT]}

At times, pregnancy occurred unplanned, then forcing decisions of whether to give birth or abort the pregnancy.

\begin{abstract}
My brother's first child was a mistake. It was their anniversary, and they celebrated, had dinner, had sex, the condom broke... So they spent the whole night talking about what the hell they should do. They decided to take a day-after pill...Three months later...she's pregnant-the pill didn't work. They had the kid. .. They were worried about having a child, because [my brother] didn't know if he was positive... [11:M/Asx/-]
\end{abstract}

Others had children after weighing the possibilities, consciously "taking the gamble" that the child would not have the mutation. Children can bring joy and continue life, and hence can be seen as helping the extended family, in some ways compensating for death(s) due to HD.

\begin{abstract}
We decided to go through it and have another baby, which was the best decision we ever made...He's just brought a lot of happiness into my family since my dad died. [8:F/Asx/NT]
\end{abstract}

\section{Roles of Others}

Usually, decisions to have children were made not unilaterally by one individual, but dyadically as part of a couple. Additionally, couples often made these reproductive decisions not in isolation, but with input from spouses, other family members, health care workers and others.

However, in each of these multiple sets of interactions, conflicts could ensue. As illustrated in Fig. 2, even within the domain of "responsibility toward others," multiple considerations exist and can compete-e.g., a spouse's preferences could conflict with an individual's sense of the best interests of a future child. Preferences of other family members (e.g., a sibling) could clash with those of a spouse. Input from a health care worker (e.g., that a cure might be developed) could counter a spouse's views or preferences. As suggested below, the outcome may depend on the nature and strength of each factor, and other forces involved in a particular individual's decision. At times, children were born because of conflict between members of a couple, who disagree in their concern about responsibility toward others-i.e., future generations. For instance, members of a couple could clash about undergoing genetic testing before having a child. One at-risk woman said,

\footnotetext{
I went back and forth with my husband. I kept telling myself: "I can't have another baby.". . .But he said: we will not have another baby if you're going to get tested first. [8:F/Asx/NT]
}

Her husband's refusal to permit her to undergo predictive testing for herself suggests the degree to which members of a couple may clash about these reproductive issues. Spouses can either agree or disagree with each other's preferences concerning having children, and may view these issues in very different ways. One woman's husband, e.g., would risk having another child, and felt they should not be too concerned about potential ethical qualms or objections. 


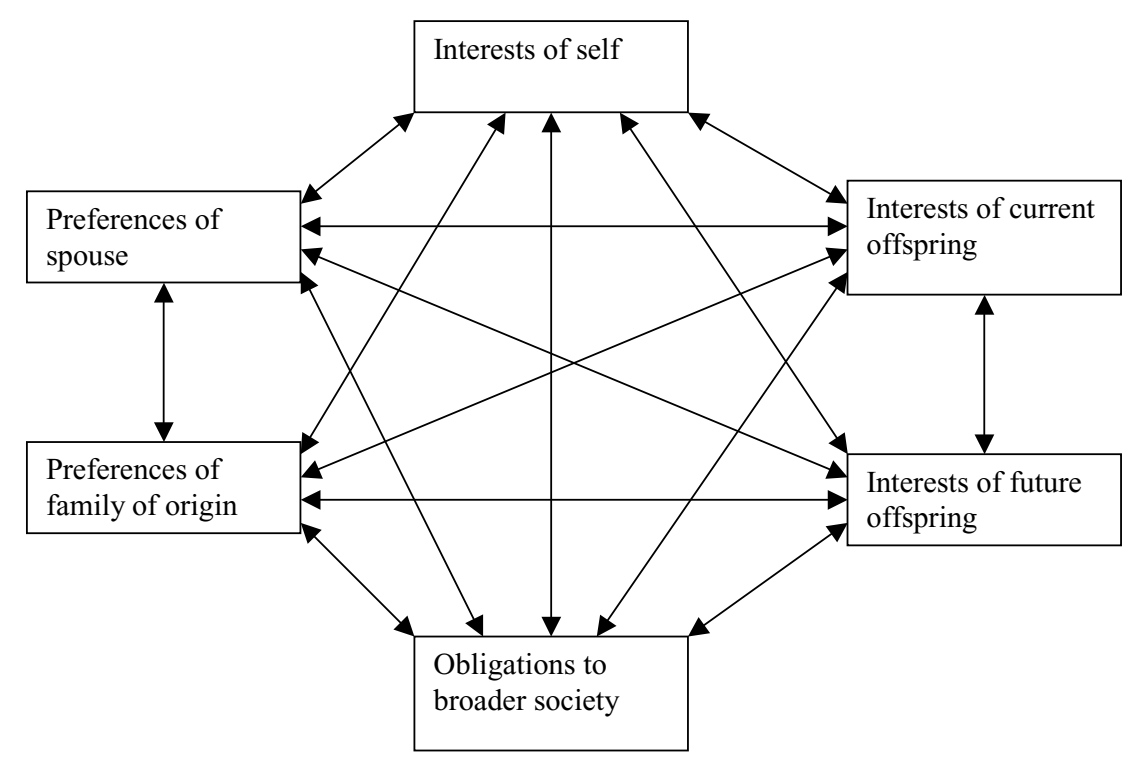

Fig. 2. Possible types of competing interests involved in reproductive decision-making.

While I was getting the testing, he was still saying he would be willing to have another baby without me going through with it...He thinks. ..there's not much control of the universe. You have to run a little rough shod over those kinds of things. You just can't live like that. ..[12:F/Asx/-]

In a dyad, power relationships may operate such that one member may overrule the other, who in turn may be forced to yield, or consider responding surreptitiously.

He was so adamant! I was going to have myself tested, and if I came out positive, I was just going to say: No, we're not have another one. I don't know. . .if I was going to admit I had the test. I never told my husband this, but I called [my OB]: "Can I come in for a blood test?" They said, "No...You have to go some other place." [8:F/Asx/NT]

While she had concerns about these issues, he did not

At-risk individuals justified decisions to have a child possibly with the mutation, and responded to possible objections that they were not acting responsibly toward others. They argued that despite being at risk of HD, one can still have a good life.

I've had a great life and wouldn't change anything. Even with HD. I don't regret being alive... [6:M/Sx/+]

The possibility that a cure may eventually be developed can further justify childbirth.
I want to have children...If I do have the disease, hopefully by then there will be...treatment. [10:F/Asx/NT]

At-risk individuals may feel that health care workers support this possibility of future treatment.

They swear that my children are not going to have to worry about it - that there's going to be a cure. [8:F/Asx/NT]

Health care workers may not actually make this specific assertion, but often express optimism about the prospect of future treatment that individuals may misinterpret or mishear.

Health care workers, too, could affect reproductive decisions in several ways. As mentioned above, health care workers could foster notions that treatment will be available in the future, though health care workers' reactions could also be negative.

I faced a lot of the judgment. . There was that awful moment when the doctor put two and two together: that we had had our son without having that test. I saw the look on her face. In a flash, I felt the full weight of her judgment: That I had done such a thing. That was excruciating. [12:F/Asx/-]

In part, this woman felt criticized, too, because of her low self-esteem, and feelings of having deserved HD. Yet such perceived criticism can engender anger and, possibly, future secrecy.

Finally, I was not telling doctors the truth-I wised up. [12:F/Asx/-] 


\section{Other Reproductive Options}

\section{Adoption}

Those opposed to giving birth to a possibly mutation-positive child faced several options, including adoption. Many would adopt, rather than risk transmitting the gene, but even here, they had to weigh varying options. Adoption might result from a sense of responsibility toward others (i.e., unwanted infants).

"If I test positive, I probably will adopt...a baby. . that someone else couldn't take care of. Let's figure out what's better. [3:M/Asx/NT]

She wanted to decide "what's better"-i.e., morally, partly since the parent could still die of HD before the child reached maturity. Adoption raised moral questions of how responsible to others to be: whether the benefits of giving an uncared-for baby a home for a period of several years outweigh the possible moral objection that the parent may eventually become incapacitated and die of HD. Moreover, as a result of the threat of a parent's eventual incapacity,

"in certain states they won't even let you adopt children." $[5: \mathrm{M} / \mathrm{Asx} /+]$

\section{Pre-Implantation Genetic Diagnosis}

As mentioned earlier, in recent years, preimplantation genetic diagnosis has become possible, and a few of those at risk have undergone this procedure, seeing advantages. Yet limitations arose. A man with HD said about his sister,

\begin{abstract}
She knows that her kids don't have the disease. They take out 10 of her eggs... and find 8 that don't have the disease, in case she has it. But if she has it, they don't tell her. Then they...put the eggs back in and don't tell her if she has it or not...So she knows her kids don't have it now, which is great for her. $[18: \mathrm{M} / \mathrm{Sx} /+]$
\end{abstract}

The advantages of this procedure are clear: allowing couples to have children who do not carry HD mutations, and avoiding informing a parent if he or she carries the mutation. Not surprisingly, several said they would consider pre-implantation genetic diagnosis if they knew they were positive, in order still to have kids.

Yet though some individuals were aware of preimplantation genetic diagnosis as a result of articles in the media and film, not everyone knew this possibility existed. Others remained wary, not seeing preimplantation genetic diagnosis as a panacea, or even realistic possibility for them, due to economic, psychological, and possibly physical costs, particularly if more than one IVF cycle is needed.

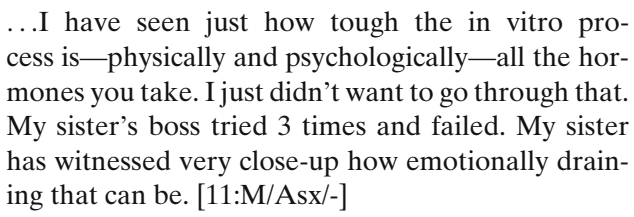

Moreover, as with childbirth or adoption, a parent with HD may not live as long as he or she would have otherwise, to raise the child.

Still, despite the limitations, pre-implantation genetic diagnosis can provide peace of mind-even if the technological details are not fully understood, and may even prompt wariness.

\section{It is all like Star Wars to us. But whatever it takes, the peace of mind is huge. [7:M/Asx/+]}

Hence, family members and health care workers may encourage or pressure at-risk individuals to undergo pre-implantation genetic diagnosis, which can also lead to conflict.

\section{We were actually trying to convince my brother to do it, but he wouldn't go. [7:M/Asx/+]}

\section{Amniocentesis or CVS, and Abortion}

Some have had, or would have amniocentesis, followed by abortion if the fetus were found to have the mutation. Yet moral concerns often arose and clashed concerning these procedures. Though desires for an abortion can reflect responsibility toward a future child, ensuring that he or she does not have the mutation, terminating a pregnancy was felt to be morally problematic and left many uncomfortable. Some judged that abortion was permissible for a very serious disease such as HD, but not for many other disorders.

I wouldn't recommend it for just any illness. It has to be something as devastating as HD. [2:M/Sx/NT]

Not all individuals who expressed interest in amniocentesis assumed they would necessarily abort a fetus if it were mutation positive. Though health care workers presumably only recommend amniocentesis or CVS if the patient expresses willingness to 
undergo abortion, at-risk individuals spontaneously pondered hypothetical questions of whether, if pregnant, they would undergo amniocentesis, and abortion, depending on the result. These individuals were aware that their views might change over time.

I think when I get pregnant, I'm going to test the fetus. But I don't know if I would want to get an abortion. I don't know if I'll be able to do it. [9:F/Asx/NT]

Here, uncertainty remains. Some wanted amniocentesis because of desires for information that can clash with moral concerns.

\begin{abstract}
I'm pro-choice. But I don't know how I'd deal with it. Why would God give me a baby that had it? Am I supposed to just abort it? It's moral values. I have nothing against it, if people have to get that done. Everybody's got their own situation. .. I'd definitely get the fetus tested. Whether I end up having it, or get an abortion - I don't know. I would just feel better if I knew. Maybe so if our child showed symptoms, he didn't have to think he was crazy, because we would know. But at the same time, the only way we can stop the disease is to not pass it along. [9:F/Asx/NT]
\end{abstract}

She remained undecided how she would resolve this dilemma, balancing innate desire for knowledge and feelings that the knowledge could help her child, against public health concerns that reflect broad social responsibility toward others.

Different sets of responsibilities toward others can thus compete in these decisions.

Overall, most interviewees opposed aborting a fetus because of HD. This opposition arose due to Catholicism, more general moral sensibilities, and fears of a moral slippery slope. A Catholic, mutationpositive man said,

\section{You could test embryos and opt for a selective abor- tion, but I'm really Catholic. It just offends my sense of morality to decide which embryo lives or dies. . .I don't feel like it's up to me. . .I might adopt. $[4: \mathrm{M} / \mathrm{Asx} /+]$}

Resistance to abortion because of HD emerged, too, for the same reason offered in support of having children despite risk for HD: individuals with HD can still have full lives before becoming ill.

\footnotetext{
My brother has HD, but is a beautiful human being. If my mother had an abortion...lot of people out there would do anything to have 30 good years. I'm taking care of him. He's not draining society. [3:M/Asx/NT]
}

Yet he implies that the fact that his brother does not use societal resources plays a role in his determination, suggesting that if his brother did use such resources, the moral equation might shift in favor of abortion. Responsibility to future children could also clash with broader ethical concerns about eugenics that may be seen as reflecting "responsibility to others" as well. Even if pro-choice, some felt they would not undergo pre-implantation genetic diagnosis or amniocentesis and abortion because of wariness of eugenics. Many opposed the possibility of "designer babies," arguing that rejection of potential babies on genetic grounds violates something sacred. In deciding to have a child, one must be prepared and accept the child no matter what. Childbirth should not be akin to ordering and returning "commercial goods."

\footnotetext{
"Oh, this person's going to have leukemia. Throw him out." I disagree with that. . .you were willing to take that risk by having a baby. You could die having a baby. If that baby is sick, you have it. That's the decision you gotta make up front. It's not like ordering a meal: you don't like it, send it back to the kitchen...It's not like buying a pair of pants. "...Please send it back and get something else." You have to accept what is given to you, and make the best of it. [3:M/Asx/NT]
}

"Responsibility toward others" can thus be defined in broad social and moral terms, as dictating that one accept one's child no matter what. Hence, notions of responsibility towards others are interpreted in various ways and could in fact clash. Other factors or considerations are then involved in, and can sway, decisions.

These moral dilemmas are often decided on instinctual grounds of whether "it sits right" or literally causes visceral upset. Opposition to abortion arose, too, due to the fact that one could oneself have been aborted.

\footnotetext{
.. Just because I'm at risk for HD doesn't mean I shouldn't have been born. What if my parents had detected it before they had kids?...[8:F/Asx/NT]
}

Many of these individuals tended not to follow intellectual principles against abortion, but to draw on visceral moral feelings. They did not rigidly follow dictates, but considered the circumstances, weighing various competing factors.

\footnotetext{
Abortion for HD just doesn't sit right with me. Not because the Church says abortion is wrong. I'm somewhat moral. It's just not right. I'm not against abortion. A woman has a choice; but the choice is made based on her ability to provide for the child. Maybe she was raped and can't have a child. [3:M/Asx/NT]
} 
Principles of autonomy (i.e., the right to make one's own abortion choices) could also conflict with notions of responsibility toward others. Many distinguished between their own reluctance to undergo an abortion vs. a legal prohibition against anyone being able to do so. These individuals would choose not to have an abortion themselves, but thought that others should be allowed to make their own choices, except for purposes of eugenics.

...With abortion, I'm definitely pro-choice, but I personally would have trouble with that...It would feel immoral to me. [11:M/Asx/-]

He was pro-choice for others, but to abort a fetus himself felt morally wrong. Hence, as an alternative, pre-implantation genetic diagnosis appealed to him.

\section{Guilt and Blame}

Conflicts arose concerning not only future reproductive decisions, but past ones as well. However, since it was too late to change what had already happened, guilt and blame could ensue. One's sense of responsibility can also change over time, as symptoms or new technologies developed. Often, those who had had children without testing now felt guilty about having done so, even though the children remained of unknown gene status.

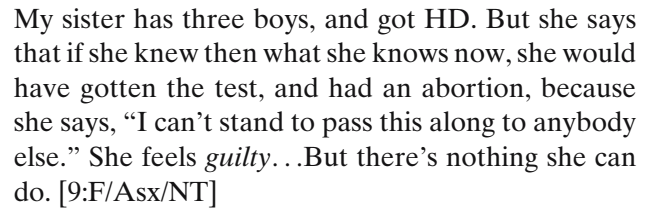

Indeed, one's first reactions to being diagnosed may be fears and regrets about the implied possible risk to offspring.

I have a daughter. I don't know if she has it or not. But I felt guilty that there was a possibility. $[20: \mathrm{M} / \mathrm{Sx} /+]$

Fear of possible guilt in the future if they had kids led many to avoid having children at all.

I don't think we could have lived with the guilt if we knew that we were at risk, and had kids anyway. $[7: \mathrm{M} / \mathrm{Asx} /+]$

Still, uncertainty hovered as to how future generations would view individuals' present decisions and the fact that tests now existed, but might not be used. Potentially in the future, children could blame parents for not preventing transmission of the genewhich deterred some from having children.

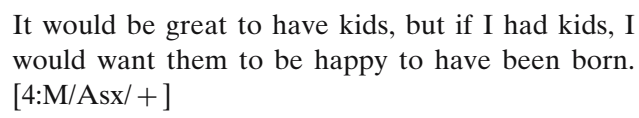

The guilt of having unwittingly transmitted the disease to one's offspring can be overwhelming. As one woman said about her father,

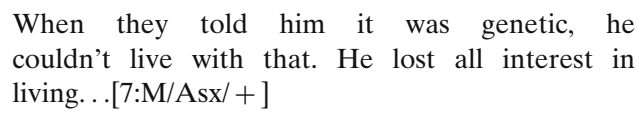

Questions arose of whether one should feel guilt about passing the mutation on to one's children. Yet such guilt could persist even when it was seen as irrational.

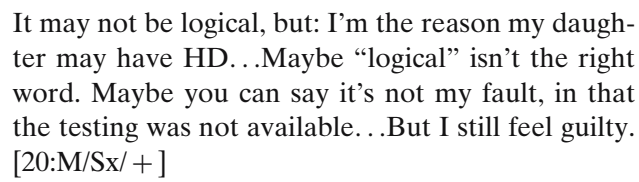

Yet others felt that such possible transmission of genes was blameless, since tests were still newunavailable until relatively recently. Some felt that to blame parents was absurd, since the transmission of many genetic predispositions-good and bad-was inevitable. Hence, one should neither blame parents nor feel responsible for passing on the mutation.

\begin{abstract}
I'm not going to blame my dad...Everybody's got something. ..there's a lot of other good stuff that he gave me...even though my life's been a little rough. .. I still like my life—who I am. [9:F/Asx/NT]
\end{abstract}

Still, concerns arose about how one's offspring might view one's decisions in the future.

\section{Abstinence from Reproduction and/or Marriage}

The fact that marriage is linked to having children may contribute to some individuals with the HD mutation avoiding serious relationships. They felt that they should not burden a spouse with potentially limited abilities to have or raise offspring. In part as a result, some individuals with the mutation avoided longer-term commitments.

\section{Weighing these Issues}

These competing moral factors and their implications proved difficult to resolve. The complexities 
and conflicts involved generated uncertainty. Some simply decided that whether they got pregnant and had a child was God's will—not theirs.

\begin{abstract}
I don't think God gives you anything you can't handle. That's why I don't know if I could deal with an abortion-because why would He give me a baby that has HD if I can't handle it? It's just too much to think about. [9:F/Asx/NT]
\end{abstract}

Given the complexity of these issues, the feeling that what happens is "all in God's hands" can offer comfort. In part, for God to give this woman a problem she could not handle would suggest that He was punishing her-an idea that was anathema to her.

One's own moral intuition can compete with larger political beliefs. A sense of broader social responsibility can lead to opposition to having a child with the mutation, because of the eventual burden to society.

It seems unfair to ask people to forgo childbearing, but at the same time, you're burdening society with people that are going to get sick. Maybe they won't get sick. Maybe the children won't have it. [13:M/Asx/-]

Interviewees generally felt ill-equipped to comment adequately on the larger political and policy issues.

I'm not the right person to answer those questions. It's a little too big. [13:M/Asx/-]

\section{CONCLUSIONS}

Individuals at risk for HD faced a difficult series of choices concerning reproductive decisions, balancing personal and various moral factors. Many individuals confronted dilemmas of whether to: get pregnant and deliver, have fetal testing and either abort or not if the fetus is positive, have pre-implantation genetic diagnosis, adopt, or have no children. In making these decisions, individuals weighed numerous, often competing, desires and concerns. While Downing (2005) presented 3 cases and emphasized responsibility toward others as a defining theme, the present data, reporting on a larger number of interviews, reveal other issues, suggesting numerous complexities and conflicts involved. These data shed important light on the role of this one factor (i.e., sense of responsibility) in relation to other variables-how it often consisted of multiple conflicting notions that individuals had to weigh against both each other, and additional competing factors. Individuals had to bal- ance their own needs and desires (e.g., for children) vs. those of spouses vs. larger ethical and moral issues. Broader moral concerns and perceptions of the best interests of current or future offspring can compete. Thus, difficult questions arose of how much and to whom to feel responsible vs. broader perceived imperatives to end the disease or follow religious and/or moral dictates (e.g., about abortion). While Downing (2005) presented a schematic "model of responsibility" that included several stages (e.g., "establish self as responsible decision-maker"), the data here highlight tensions that may be involved in such determinations and stages: others' perceptions of an individual's responsibilities may differ from that of the individual him or herself and conflicts can ensue and persist.

Not surprisingly, over time with each pregnancy, some individuals here were uncertain and/or changed their perspectives and decisions (e.g., "taking the gamble" with a first pregnancy, but subsequently being more cautious, using pre-implantation genetic diagnosis, or avoiding other pregnancies altogether). Family members often also voiced preferences and pressured individuals about these reproductive issues.

Though pro-choice in general, many individuals would not undergo abortions themselves, and had qualms about aborting a fetus because it had the HD mutation. Prevention of HD was viewed as a morally insufficient and unacceptable rationale for abortion. Thus, varying notions of social and moral responsibility led to different pro-choice stances that were not necessarily unequivocally pro-choice, but depended on the reasons and situations involved. Many women were pro-choice but anti-eugenics, suggesting that social concerns about eugenics could outweigh feelings about autonomy and rights to individual choice, because of the social implications involved. Indeed, women undergoing abortions have been found to undergo complex emotions related to age, beliefs about the fetus, socio-economic status, self-efficacy, guilt, and blame (Coleman et al., 2005).

As suggested by the Health Belief Model, individuals do indeed weigh pros and cons concerning their decisions, but, importantly, many factors (e.g., moral values about eugenics, and current and future children) also enter into these decisions. While the Health Belief Model is largely a rational decision model, these data highlight emotional, moral, unconscious, and imagined factors as well. Whether individuals here seek or avoid information (e.g., through amniocentesis or pre-implantation genetic diagnosis) 
appears tempered by a range of other intra- and inter-personal factors. Despite Stages of Change models, although an individual's earlier reproductive decisions (e.g., about pregnancies) may affect later ones, sexual behavior is not always planned, and reproductive decisions are often dyadic, not unilateral. Thus, these data highlight, the limitations of some of these theoretical models, and the need for developing appropriately nuanced frameworks for understanding these complex, multi-faceted issues.

In making decisions about conflicting underlying ethical issues, complicated ethical dilemmas rarely involve "good vs. evil," but more often, weighing competing ethical goods (Hundert, 1987). Individuals have to balance responsibilities toward others vs. their own needs. Additionally, an individual's beliefs and principles can conflict and compete, rather than be clear. Individuals also often had difficulty knowing how to resolve these dilemmas and make decisions. Given that these dilemmas are complex (e.g., requiring weighing of desires for children against possible future guilt), at times these choices may not be consciously "decided." Rather, some pregnancies occurred without planning, or before HD risks were known or fully acknowledged. Unconscious psychological defenses such as denial may play important roles in these outcomes. When couples disagree, decisions may be deferred, one party may prevail, or a compromise may be reached. Notions of responsibility toward others are in part subjective, involving interpretation and application of moral principles that can vary. Thus, though Downing (2005) suggests that individuals present themselves as acting responsibly, more complex and nuanced questions emerge.

Several specific issues arose concerning preimplantation genetic diagnosis - use of which appeared limited by cost, and knowledge of the procedure's existence. The fact that not all at-risk individuals knew about pre-implantation genetic diagnosis underlines the need for more education about this option. Yet understanding of reproductive and genetic technologies can be difficult. Pre-implantation genetic diagnosis also remains controversial, and along with other reproductive technologies (e.g., abortion and stem cell research) has generated intense political debate, fueled in part by fears, and religious and moral objections. Preimplantation genetic diagnosis has been outlawed or strictly regulated in several European countries (Robertson, 2005), and is controversial in the U.S. as well (Healy, 2003). Concerns arose in these data that in the future, if pre-implantation genetic diagnosis use spreads, norms may change, such that its use becomes expected. Some parents wondered if they would be blamed for not using this procedure and then having mutation-positive children. Thus, in coming decades, individuals born with the HD mutation (i.e., for whom pre-implantation genetic diagnosis was not performed) may encounter increased stigma.

Though thoughts arose of testing a fetus without undergoing abortion, clinicians would presumably oppose such prenatal testing if parents would not agree in advance to terminate the pregnancy. Parents' right to know a fetus' gene status for its own sake has no clear medical benefit, and the knowledge might in fact affect parental upbringing in ways that could harm the child. In upcoming years as more genetic tests become available, patterns and reasons concerning abortions may also change. Among multiple reasons to seek abortion, women have commonly cited wanting to postpone or stop childbearing, and socioeconomic factors, and only $13 \%$ in the US in 1987 and 7\% in Australia in 1992 cited possibility of a fetal defect (Bankole et al., 1998; Sihvo et al., 2003).

The present data have important implications for health care workers. Providers need to be as aware as possible of how reproductive decisions are viewed and made within the complexities of couple dyads. Most doctors would like to be involved in post-test counseling and support (Thomassen et al., 1993), but may not in fact have the training or expertise to do so. Health care workers need to be able to raise and address these topics with patients and couples as part of medical care, and learn how to do so. Currently, health care workers may work closely with only the one at-risk individual, yet spouses may agree or disagree about these reproductive choices, posing dilemmas of how health care workers should address and mediate spousal conflict. If a husband insists that an at-risk spouse not get tested before becoming pregnant, should the staff intervene, and support the at-risk individual's insistence on getting tested first? If the disagreement persists, does the woman and/or the at-risk individual have more decision-making power, or should the decision be entirely mutual within the couple?

Though the principle of autonomy can dictate that these choices be left wholly up to the individual, questions arose of whether health care workers have-or feel they have-any ethical obligations in these decision-making processes, and if so what. Dilemmas emerge of whether, when, how, and to what degree health care workers should inform 
at-risk individuals, or encourage them to consider these various options. Arguably, genetic counselors and other health care workers should ensure that atrisk individuals are as aware as possible of the existence and availability of pre-implantation genetic diagnosis.

More psychosocial services may help at-risk individuals confront these difficult choices. The fact that these quandaries can hamper at-risk individuals in entering or maintaining committed relationships further underscores needs for psychotherapeutic services to help in confronting these issues and the potential effects of gene status on self-esteem, and appropriate decision-making. Indeed, these findings suggest that couples therapy may often be helpful in not only genetic testing decisions, as Richards and Williams' (2004) recommended, but reproductive decision-making about HD as well. Health care workers may tend to work with at-risk individuals concerning whether or not to undergo genetic testing - but not how to make reproductive decisions. The Huntington's Disease Society of America advocates a team approach, but it is not clear how these issues in fact get addressed: by whom, when, how well, and to what degree.

Further research is important to understand these patterns of dyadic decision-making, the factors involved, the knowledge and comfort of at-risk individuals, medical trainees and health care workers concerning these technologies, the training of genetic counselors and other health care workers to handle these complex psychological issues (e.g., denial and avoidance), the degree to which genetic counselors and other health care workers become involved in these complex aspects of reproductive decision-making, the ways health care workers do and should approach these conflicts and best work with both members of a disagreeing couple, and whether and in what ways health care workers would benefit from additional training. Future investigations can explore, too, the rates at which differing attitudes prevail, and possible differences in decisionmaking based on clients' gender; risk status of the woman, and other factors.

This study has several potential limitations. These individuals are involved with a tertiary care center, yet provided key insights into responses toward HD by parents, siblings, and extended relatives elsewhere, too. We were unable to test statistically relationships regarding gender, ethnicity, socioeconomic status, testing, and symptom status. However, overall, these data reveal several suggestive and im- portant themes that can be pursued further in future research with larger samples. We interviewed participants at one point in time only, but they described their past as well as present history of HD-related experiences. These data also appear to have a certain face validity.

Importantly, these data have several policy implications. The fact that those with HD may face obstacles in being able to adopt children poses critical policy concerns. The 1994 Federal Uniform Adoption Act provided some general guiding principles (Uniform Adoption Act, 1994), but grey areas exist in how agencies evaluate the "physical and mental health" of prospective parents. Anecdotally, at least some adoption agency application forms inquire about genetic disease in the family. Future research needs to assess variations among application forms and specific criteria of adoptions agencies.

Increasingly over time these issues will be critical as more genetic tests become available, including tests for incompletely penetrant diseases and genetic modifiers that are normal variants that might influence treatment responses or disease progress. How genetic counselors and health care workers as a whole currently face these issues remains unknown, but heightened training and research can help in preparing genetic counselors, other health care workers, and at-risk individuals to confront these complexities as optimally as possible.

\section{APPENDIX. A. Sample Questions from Semi-Structured Interview Guide}

- When did you learn that you were at risk of $\mathrm{HD}$, and what was your reaction to it at that time?

- How do you feel about being at risk of HD?

- Have you had genetic testing done?

- If so, what was the result, and how did you respond?

- How did you decide whether to have genetic testing done or not?

- How has being at risk for HD affected you?

- Do you have children? If so, how many?

- How have you made decisions about having children?

- Has HD affected your decisions to have children in any way? If so, how?

- Has HD affected decisions by other members 
of your family about having children? If so, how?

- Do you have any other thoughts about these issues?

\section{ACKNOWLEDGMENTS}

The authors would like to thank Kristin Skrabut, Renée C. Fox, Mary DuVernay, Carol Moskowitz, and Paula Lieber for their assistance with this manuscript. Funding for this research was provided through grant 5-R01-HG002431-01 from the National Human Genome Research Institute.

\section{REFERENCES}

Adam, S., Wiggins, S., Whyte, P., Bloch, M., Shokeir, M. H. K., Soltan, H., Meschino, W., et al. (1993). Five year study of prenatal testing for Huntington's disease: Demand, attitudes, and psychological assessment. J Med Gen, 30, 549-556.

Alonso Vilatela, M. E., Ochoa Morales, A., Garcia de la Cadena, C., Ruiz Lopez, I., Martinez Aranda, C., \& Villa, A. (1999). Predictive and prenatal diagnosis of Huntington's disease: Attitudes of Mexican neurologists, psychiatrists, and psychologists. Arch Med Res, 30(4), 320-324.

Bankole, A., Sing, S., \& Haas, T. (1998). Reasons why women have induced abortions: Evidence form 27 countries. Int Fam Plan Perspect, 24(3), 117-152.

Braude, P. R., De Wert, G. M., Evers-Kiebooms, G., Pettigrew, R. A., \& Geraedts, J. P. (1998). Non-disclosure preimplantation genetic diagnosis for Huntington's disease: Practical and ethical dilemmas. Prenat Diagn, 18, 1422-1426.

Broadstock, M., Michie, S., \& Marteau, T. (2000). Psychological consequences of predictive genetic testing: A systematic review. Eur J Human Genet, 8, 731-738.

Case, D., Andrews, J. E., Johnson, J. D., Allard, S. L. (2005). Avoiding versus seeking: The relationship of information seeking to avoidance, blunting, coping, dissonance, and related concepts. J Med. Libr Assoc, 93, 353-362.

Coleman, P. K., Reardon, D. C., Strahan, T., \& Cougle, J. R. (2005). The psychology of abortion: A review and suggestions for future research. Psychol Health, 20, 237-271.

Craufurd, D., Dodge, A., Kerzin-Storrar, L., \& Harris, R. (1989). Uptake of presymptomatic predictive testing for Huntington's disease. Lancet, 2(8663), 603-605.

Creighton, S., Almqvist, E. W., MacGregor, D., Fernandez, B., Hogg, H., Beis, J., Welch, J. P., et al. (2003). Predictive, prenatal and diagnostic genetic testing for Huntington's disease: The experience in Canada from 1987 to 2000. Clin Genet, 63, $462-475$.

Delatycki, M. B. (2003). Commentary on Spriggs: Genetically selected baby free of inherited disposition to early onset Alzheimer's disease. J Med Ethics, 29, 120.

Downing, C. (2005). Negotiating responsibility: Case studies of reproductive decision-making and prenatal genetic testing in families facing Huntington Disease. J Genet Counseling, 14(3), 219-234.

Drake, H., Reid, M., \& Marteau, T. (1996). Attitudes towards termination for fetal abnormality: Comparisons in three European countries. Clin Genet, 49, 134-140.

Elger, B., \& Harding, T. (2003). Huntington's disease: Do future physicians and lawyers think eugenically? Clin Genet, 64(4), 327-338.
Evers-Kiebooms, G., Nys, K., Harper, P., Zoetewij, M., Dürr, A., Jacopini, G., Yapijakis, C., \& Simpson, S. (2002). Predictive DNA-testing for Huntington's disease and reproductive decision making: A European collaborative study. Eur J Hum Genet, 10, 167-176.

Folkman, S., \& Lazarus, R. S. (1980). An analysis of coping in a middle-aged community sample. J Health Soc Behav, 21(3), 219-239.

Geertz, C. (1973). Interpretation of cultures: Selected essays. New York: Basic Books.

Goizet, C., Lesca, G., \& Durr, A. (2002). Presymptomatic testing in Huntington's disease and autosomal dominant cerebellar ataxias. Neurology, 59, 1330-1336.

Hayden, M. (2000). Predictive testing for Huntington's disease: The calm after the storm. The Lancet, 356, 1944-1945.

Healy, M. (2003). Embryo diagnosis stirs controversy. The Los Angeles Times, July 29, 2003.

Henn, W. (2000). Consumerism in prenatal diagnosis: A challenge for ethical guidelines. J Med Ethics, 26(6), 444-446.

Houlihan, G. D. (1999). The evaluation of the 'stages of change' model for use in counselling client's undergoing predictive testing for Huntington's disease. J Adv Nursing, 29, 11371143.

Hundert, E. M. (1987). A model for ethical problem solving in medicine, with practical applications. Am J Psychiatry, 144, 839-846.

Johannes, L. (2004). A screening test for high-risk mothers. Wall Str J, Nov. 23, 2004

Kahneman, D., Tversky, A. (1974). Judgment under uncertainty: Heuristics and biases. Science, 184, 1124-1131.

Kero, A., Högberg, U., Jacobsson, L., \& Lalos, A. (2001). Legal abortion: A painful necessity. Soc Sci Med, 53, 1481-1490.

Kero, A., Lalos, A., Högberg, U., \& Jacobsson, L. (1999). The male partner involved in legal abortion. Hum Reprod, 14, 2669-2675.

Kessler, S., Field, T., Worth, L., \& Mosbarger, H. (1987). Attitudes of persons at risk for Huntington disease toward predictive testing. Am J Med Genet, 26(2), 259-270.

Kirshenbaum, S. B., Hirky, A. E., Correale, J., Goldstein, R. B. Johnson, M. O., Rotheram-Borus, M. J., \& Ehrhardt, A. A. (2004). Throwing the dice: Pregnancy decision-making among HIV-positive women in four U.S. cities. Perspect Sex Reprod Health, 36(3), 106-113.

Klitzman, R. (1997). Being positive: The lives of men and women with HIV. Chicago: Ivan R. Dee, Inc.

Klitzman, R., \& Bayer, R. (2003). Mortal secrets: Truth and lies in the age of AIDS. Baltimore: Johns Hopkins University Press.

Lavery, S. A., Aurell, R., Turner, C., Castellu, C., Veiga, A., Barri, P. N., \& Winston, R. M. (2002). Preimplantation genetic diagnosis: patients' experiences and attitudes. Hum Reprod, 17, 2464-2467.

Lesca, G., Goizet, C., \& Dürr, A. (2002). Predictive testing in the context of pregnancy: Experience in Huntington's disease and autosomal dominant cerebellar ataxia. J Med Genet, 39, 522-525.

Littell, J. H., \& Girvin, H. (2002). Stages of change: A critique. Behav Modif, 26, 223-273.

Maat-Kievit, A., Vegter-van der Vlis, M., Zoeteweij, M., Losekoot, M., van Haeringen, A., Kanhai, H., \& Roos, R. (1999). Experience in prenatal testing for Huntington's disease in The Netherlands: procedures, results and guidelines (1987-1997). Prenat Diagn, 19, 450-457.

Markel, D. S., Young, A. B., \& Penney, J. B. (1987). At-risk persons attitudes toward presymptomatic and prenatal testing of Huntington disease in Michigan. Am J Med Genet, 26, 295305.

Mastromauro, C., Myers, R. H., \& Berkman, B. (1987). Attitudes toward presymptomatic testing in Huntington disease. $A m \mathrm{~J}$ Med Genet, 26(2), 271-282. 
Meiser, B., \& Dunn, S. (2000). Psychological impact of genetic testing for Huntington's disease: An update of the literature. J Neurol Neurosurg Psychiatry, 69, 574-578.

Meissen, G. J., \& Berchek, R. L. (1987). Intended use of predictive testing by those at risk for Huntington disease. Am J Med Genet, 26(2), 283-293.

Richards, F. (2004). Couples' experiences of predictive testing and living with the risk or reality of Huntington Disease: A qualitative study. Am J Med Genet, 126A, 170-182.

Richards, F. H., \& Rea, G. (2005). Reproductive decision making before and after predictive testing for Huntington's disease: An Australian perspective. Clin Genet, 67, 404-411.

Richards, F., \& Williams, K. (2004). Impact on couple relationships of predictive testing for Huntington Disease: A longitudinal study. Am J Med Genet, 126A, 161-169.

Robertson, J. A. (2005). Ethics and the future of preimplantation genetic diagnosis. Reproductive BioMedicine Online www.rbmonline.com, 10 Supp. 197-101.

Robertson, J. A. (2003). Extending preimplantation genetic diagnosis: The ethical debate: Ethical issues in the new uses of preimplantation genetic diagnosis. Hum Reprod, 18, 465471.

Robins-Wahlin, T. B., Backman, L., Lundin, A., Haegermark, A., Winblad, B., \& Anvret, M. (2000). High suicidal ideation in persons testing for Huntington's disease. Acta Neurologica Scandinavica, 102(3), 150-161.

Rosenstock, I. M., Strecher, V. J., \& Becker, M. H. (1988). Social learning theory and the Health Belief Model. Health Educ Q, $15,175-183$.

Sermon, K., DeRijcke, M., Lissens, W., DeVos, A., Platteau, P., Bonduelle, M., Devroey, P., et al. (2002). Preimplantation genetic diagnosis for Huntington's disease with exclusion testing. Eur J Human Genet, 10, 591-598.

Sihvo, S., Bajos, N., Ducot, B., Kaminski, M., \& the Cocon Group (2003). Women's life cycle and abortion decision in unintended pregnancies. J Epidemiol Community Health, 57, 601605.

Simpson, S. A., Harper, P. S., \& United Kingdom Huntington's Disease Prediction Consortium. (2001). Prenatal testing for Huntington's disease: Experience within the UK 1994-1998. J Med Genet, 38(5), 333-335.

Sobel, S. K., \& Brookes Cowan, D. (2000). Impact of genetic testing for Huntington Disease on the family system. Am J Med Genet, 90, 49-59.
Spriggs, M. (2002). Genetically selected baby free of inherited predisposition to early-onset Alzheimer's disease. J Med Ethics, $28,290$.

Stern, H. J., Harton, G. L., Sisson, M. E., Jones, S. L., Fallon, L. A., Thorsell, L. P., Getlinger, M. E., et al. (2002). Nondisclosing preimplantation genetic diagnosis for Huntington disease. Prenat Diagn, 22, 503-507.

Sorenson, J. R., \& Wertz, D. C. (1986). Couple agreement before and after genetic counseling. Am J Med Genet, 25, 549-555.

Strauss, A., \& Corbin, J. (1990). Basics of qualitative researchtechniques and procedures for developing grounded theory. Newbury Park: Sage Publications.

Taylor, S. D. (2005). Predictive genetic test decisions for Huntington's Disease: Elucidating the test/no-test dichotomy. $J$ Health Psychol, 10, 597-612.

Taylor, C. A., \& Myers, R. H. (1997). Long-term impact of Huntington Disease linkage testing. Am J Med Genet, 70, 365-370.

Thomassen, R., Tibben, A., Niermeijer, M. F., vand der Does, E., van de Kamp, J. J. P., \& Verhage, F. (1993). Attitudes of Dutch general practitioners towards presymptomatic DNAtesting for Huntington disease. Clin Genet, 43, 63-68.

Tibben, A., Duivenvoorden, H. J., Vegter-van der Vlis, M., Niermeijer, M. F., Frets, P. G., van de Kamp, J. J., Roos, R. A., Rooijmans, H. G., \& Verhage, F. (1993). Presymptomatic DNA Testing for Huntington Disease: Identifying the Need for Psychological Intervention. Am J Med Genet, 48, 137144.

Towner, D., \& Loewy, R. S. (2002). Ethics of preimplantation diagnosis for a woman destined to develop early-onset Alzheimer disease. JAMA, 287, 1038-1040.

Tversky, A., \& Kahneman, D. (1981). The framing of decisions and the psychology of choice. Science, 211, 453-458.

Tyler, A., Quarrell, O. W., Lazarou, L. P., Meredith, A. L., \& Harper, P. S. (1990). Exclusion testing in pregnancy for Huntington's disease. J Med Genet, 27, 488-495.

Uniform Adoption Act. (1994). Available at www.law.upenn.edu/ bll/ulc/fnact99/1990s/uaa94.htm. Accessed March 27, 2006.

Verlinsky, Y., Rechitsky, S., Verlinsky, O., Masciangelo, C., Lederer, K., \& Kuliev, A. (2002). Preimplantation diagnosis for early-onset Alzheimer disease caused by V717L mutation. JAMA, 287, 1018-1021.

Wertz, D. C., \& Sorenson, J. R. (1986). Client reactions to genetic counseling: Self-reports of influence. Clin Genet, 30, 494-502. 